\title{
José-Maria de Heredia poète du Parnasse, éd. Yann Mortelette
}

\section{Maria Emanuela Raffi}

\section{Q OpenEdition \\ 1 Journals}

\section{Edizione digitale}

URL: http://journals.openedition.org/studifrancesi/8999

DOI: 10.4000/studifrancesi.8999

ISSN: 2421-5856

\section{Editore}

Rosenberg \& Sellier

\section{Edizione cartacea}

Data di pubblicazione: 1 octobre 2008

Paginazione: 482

ISSN: 0039-2944

\section{Notizia bibliografica digitale}

Maria Emanuela Raffi, «José-Maria de Heredia poète du Parnasse, éd. Yann Mortelette», Studi Francesi

[Online], 155 (LII | II) | 2008, online dal 30 novembre 2015, consultato il 13 janvier 2021. URL: http:// journals.openedition.org/studifrancesi/8999; DOI: https://doi.org/10.4000/studifrancesi.8999

Questo documento è stato generato automaticamente il 13 janvier 2021.

\section{(c) (i) (9)}

Studi Francesi è distribuita con Licenza Creative Commons Attribuzione - Non commerciale - Non opere derivate 4.0 Internazionale. 


\title{
José-Maria de Heredia poète du Parnasse, éd. Yann Mortelette
}

\author{
Maria Emanuela Raffi
}

\section{NOTIZIA}

José-Maria de Heredia poète du Parnasse, éd. Yann MORTELETTE, Paris, Presses de l'Université Paris-Sorbonne, 2006, pp. 204.

1 Volume che raccoglie e amplia i contributi di un colloque in onore di Heredia nel centenario della sua morte (1905), la raccolta di 12 articoli curata da Yann Mortelette è organizzata in due parti, una dedicata ai rapporti del poeta con autori del suo tempo, l'altra interamente consacrata ai Trophées. Mentre i primi tre articoli sembrano più legati ad avvenimenti e curiosità di carattere biografico (Robert FLEURY, Heredia administrateur de la bibliothèque de l'Arsenal, Michael PAKENHAM, Heredia et "Les Vacances d'un académicien" de Hugues Rebell, Jean-Paul Goujon, Littérature et bibliophilie dans la correspondance Heredia-Louÿs), con lo studio di Yann MORTELETTE, Correspondance et poésie, si entra nei numerosi rapporti di corrispondenza con altri autori intrattenuti da Heredia. La corrispondenza è anzi interpretata da Mortelette come il sostrato dell'opera poetica: il critico vi ritrova l'origine di alcuni testi dei Trophées, nonché i fondamenti di una poetica mai espressa da Heredia in una forma organizzata ed esplicita. In Heredia et Mallarmé. Une amicale compréhension, Jean-Luc STEINMETZ ripercorre i rapporti di cordiale scambio di opere e di suggestioni poetiche fra Mallarmé e Heredia, che trova momenti particolarmente significativi nell'invio di un esemplare del Faune con dedica a Heredia e nella serie di consigli di Mallarmé sulla composizione dei Trophées, che gli vengono poi puntualmente inviati dall'autore. Il lungo studio di JeanMarc HOVASSE, Les hommages de Heredia à Hugo si occupa invece di un rapporto molto più che biografico, dato che Les Trophées sono stati più volte accostati alla Légende des siècles e che l'accusa di fare della poesia "façon Hugo" è stata la prima mossa da Barbey d'Aurevilly a Heredia. Ma il rapporto con Hugo va al di là di questo accostamento e, 
come mostra Hovasse, comprende una lunga serie di scambi poetici, non sempre convergenti, talvolta segno di una difficile discendenza mai del tutto risolta non ostante la mediazione di Leconte de Lisle. L'ultimo articolo della prima parte, Heredia et les artistes de son temps di Patrick ABSALON, allarga lo studio delle relazioni di Heredia con i suoi contemporanei a pittori e scultori, da Moreau a Puvis de Chavanne, da Paul Baudry a Claudius Popelin e a molti altri.

2 La seconda parte del volume, dedicata ai Trophées, prende avvio con uno studio sulle nozioni fondamentali implicate nella raccolta di Heredia: l'idea di "trophée", la funzione della forma del sonetto (Edgard PICH, Il y a sonnet et sonnets). Lo studio che ne deriva passa necessariamente per l'opera poetica di Leconte de Lisle, maestro di Heredia, per le anomalie metriche e di forma della raccolta, per la visione della modernità implicita nei Trophées e, infine, per lo specifico uso del sonetto che Pich studia ed esemplifica con precisione, arrivando a teorizzare il carattere di "poème en sonnets" della raccolta, serie di trofei non unificabili «qui assument totalement une problématique des ruines». Peter HAMBLY, in Les sources des sonnets "Michel-Ange" et "Le Vase", analizza le fonti dei due sonetti indicati, approfondendo soprattutto i legami di Heredia con Gautier e Banville anche dal punto di vista lessicale, ma indicando anche interessanti prossimità con l'opera e la concezione poetica di Mallarmé. Imagination et théâtralité dans "Les Trophées" di Anne BOUVIER-CAVORET sposta l'attenzione sull'immaginazione e la scrittura da poeta drammatico di Héredia, che nei Trophées mette in scena «la mémorisation et la célébration de tous les grands moments de l'histoire et de l'art humains». La capacità di condensare i concetti nella breve forma del sonetto e di produrre sonetti-gemme, pietrificati in nome di una sopravvivenza eterna, è ciò che Jean DE PALACIO mette al centro del suo studio su Heredia, introducendo nella filiazione da Gautier il legame parallelo, ma non secondario, con Un livre de sonnets di Claudius Popelin. Chiude la serie di studi Les "Sonnets épigraphiques" de Heredia: un palimpseste lapidaire, in cui Marie-France DAVID-DE PALACIO illustra il carattere "archéologico-poétique" della raccolta dei Sonnets épigraphiques, serie di componimenti poetici scritti da Heredia come amplificazioni di epigrafi latine, perfetta combinazione decadente, secondo l'autrice, che associa «l'évocation de la primitivité à une réalisation formelle proche de la préciosité».

3 Il volume è arricchito da una serie di illustrazioni e riproduzioni di manoscritti. 